\title{
Effects of Tennis Match-induced Fatigue on Serve Performance in College Tennis Team Players 比賽情境下引發的運動疲勞對大專生網球發球表現之影響
}

\author{
LI Chunxiao SAM Kalam CHEN Shihui \\ Department of Health and Physical Education, \\ The Hong Kong Institute of Education, HONG KONG
}

\section{李春曉 岑嘉林 陳道喗}

香港教育學院健康與體育學系

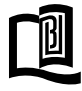

\begin{abstract}
The aim of this study was to determine whether fatigue induced by a match-like protocol could impose a negative impact on tennis service accuracy and speed. Participants $(\mathrm{N}=8)$ served balls in both rested and after match-like protocol conditions. The result indicated that the match-like protocol did not influence both the service accuracy (.785, p<.05) and speed (-.487, p<.05). It was concluded that the match inducted fatigue may not influence the speed and accuracy of the tennis serve, at least on the male college team players. Further study should be conducted by including more participants with varying tennis playing levels or experiences. Female tennis players should be included in future studies to explore if fatigue affects gender differently.
\end{abstract}

Keywords: match-like, RPE, score, speed

摘 要

本文的目的在於探索模擬比賽情境下所引發的運動疲勞是否會對網球運動員的發球準度和速度產生影響。8名高校網球校隊 隊員在熱身後, 和真實比賽環境后進行了發球測試。結果發現模擬比賽環境下所引發的運動㽻勞並未對發球的准度 $(\mathrm{p}=.785)$ 和 速度 $(\mathrm{p}=-$-.487) 產生影響。未來的相關研究有必要招募不同水平的網球運動員來探索比賽情境下引發的運動疲勞是否會對發球表 現造成影響。另外，性別差異也是一個值得關注的研究內容。

關鍵字：比賽情境, 疲勞感, 精確度, 球速

\section{Introduction}

Tennis is a popular sport competitive sport and recreational sport for people of all ages (Perry, Wang, Feldman, Ruth \& Signorile, 2004). There are an increasing number of active tennis players in the world (Gioftsidou, Malliou, Pafis, Beneka, Godolias \& Maganaris, 2006). A mixture of anaerobic skills (e.g. speed, agility and power) and aerobic capabilities are needed for competitive tennis athletes (Kovacs, 2007). As an intermittent sport, tennis is often performed over a prolonged duration (Hornery, Farrow, Mujika \& Young, 2007) and it might be better to classify tennis as an anaerobic predominant activity, which requires high levels of aerobic conditioning (Kovacs, 2006). Although tennis matches vary substantially in duration in traditional first player to win two sets matches, a tentative time of 1.5 hours has been suggested as a typical average match length (Bergeron, Maresh, 
Armstrong et al., 1995). In addition, the work-to-rest ratios of competitive tennis athletes range between 1:3 and 1:5 during the matches and fatigue is generally observed (Kovacs, 2007).

Fatigue, from a physiological perspective, can be defined as an acute impairment of exercise performance, which ultimately leads to the incapacity to produce maximal force output and/or control motor function (St Clair Gibson, Baden \& Lambert, 2003). Fatigue is a common explanation for overt performance reductions during tennis match play. It is not uncommon to perceive that the onset of fatigue is accompanied by a decline in skill. Fatigue has been shown to have a negative impact on a player's mechanics (Murray, Cook, Werner, Schlegel $\&$ Hawkins, 2001). Fatigue may be the cause of missed strokes, poor timing, an inability to position oneself properly or early enough, and general languor (Davery, Thorpe \& Williams, 2002).

Several controlled experiments have attempted to quantify the effects of fatigue on tennis skills, but performance deterioration has not been consistently reported (Davey, Thorpe \& Williams, 2002; Vergauwen, Spaepen, Lefevre \& Hespel, 1998). For example, fatigue has been shown to reduce tennis-hitting accuracy (e.g., Vergauwen, Spaepen, Lefevre \& Hespel, 1998; Davey, Thorpe \& Williams, 2002; Davey, Thorpe \& Williams, 2003).On the contrary, Ferrauti et al. (2001) found that the number of target hits increased and the number of errors decreased when players were fatigued.

While the above controlled experiments have examined the effects of fatigue on tennis skill and performance, the findings or implications of these findings should be interpreted cautiously (Hornery, Farrow, Mujika \& Young, 2007). An initial critique of the typical methodologies employed revealed flaws in terms of experimental protocols utilized (Hornery, Farrow, Mujika \& Young, 2007). The level of fatigue induced in these controlled experiments is beyond that of match play (e.g. it is highly unlikely that players under match conditions would experience this degree of physiological strain (reported peak blood lactate level was $9.6 \pm 0.9 \mathrm{mmol} /$ L), challenges the application of the findings and encourages examination of performance under matchlike conditions. In other words, the protocol employed in these controlled experiments would induce the intended fatigue, but is not representative of the physiological strain encountered during a match setting (Bergeron, Maresh, Kraemer et al., 1991).

Collectively, although attempts have been made to quantify the effect of fatigue on tennis performance, protocols employed in the previous investigations were not well simulated as a tennis match and the findings were inconsistent. Thus, the purpose of this research was to extend the former research under a simulated playing environment. More specifically, our study was going to document the differences of serve performance (accuracy and velocity) between rested and fatigue conditions under a simulated match-like protocol. The hypothesis in this study was that fatigue adversely affects tennis players' service performance.

\section{Methodology}

\section{Participants}

Eight male college tennis team players (see Table 1) volunteered to join this experiment and their informed consent to participate was collected before the experiment. Participants were allowed to quit at any time during the experiment. Ethics approval was obtained before the study from the Ethics Committees of the Institute.

Table 1. Participants' Descriptive Statistics.

\begin{tabular}{lccccc}
\hline & $\mathrm{N}$ & Min & Max & Mean & SD \\
\cline { 2 - 5 } Height (cm) & 8 & 164.00 & 190.00 & 176.25 & 9.00 \\
Mass (kg) & 8 & 51.00 & 87.00 & 67.18 & 10.93 \\
Age (year) & 8 & 20.00 & 24.00 & 21.62 & 1.18 \\
Experience (year) & 8 & .30 & 4.00 & 2.04 & 1.45 \\
\hline
\end{tabular}




\section{Measurements}

A radar gun (K15 Doppler Radar, M.P.H. Industries, Inc, Owenshoro, KY) was positioned behind the baseline of the court in order to measure the ball rebound speed after serve. A Polar Watch (S625X) was used to monitor the players' Heart Rate (HR) during the test. Ratings of perceive exertion (RPE) were obtained using the 20-category Borg RPE scale (Borg, 1998) both before and immediately after the match-like protocol. Borg's scale is widely used to measure perceived exertion, exercise intensity or fatigue (Chen, Fan, \& Moe, 2002).

\section{Procedures}

A repeated measures design was used to determine the effects of fatigue tennis serve performance. Participants were asked to serve on both before and after the matchinduced fatigue following the procedures. The simulated match-play environment for leading to fatigue condition in this study was a general single tennis competition which last for 1.5 hours (Bergeron, Maresh, Armstrong et al., 1995). Each simulated match-play was played between two randomly chosen players (subjects) under International Tennis Federation rules. Each player completed one simulated match-play.

All participants were permitted a 10 minutes warmup followed by serve test (pretest), match-induced fatigue, and serve test (posttest). The test is the sum of the service placement and the average speed of the eight trails (Knudson, Noffal, Bahamonde, Bauer, \& Blackwell, 2004).
For serves, participants were asked to stand at either side of the center baseline and serve balls as they do during competition. Each participant was permitted to practice three serves before attempting the ten formal trails. Each trial consisted of a second service attempt if the first was a fault. The strategy of second service attempts (if applicable) depend on players' own playing styles (e.g. lower speed and more spin) in real competition. The speed of the each ball was checked by an electronic radar gun and recorded by the tester.

Radar gun has widely applied to measure service speed in studies for improving service performance (e.g. Cohen et al., 1994; Treiber et al., 1998). The accuracy of radar gun has been verified to within $0.45 \mathrm{~m} / \mathrm{s}$ (1 mph) through the use of a tuning fork. The radar gun was positioned behind the right baseline of the court if players served from left-half court to right-half court and vice versa.

The placement (accuracy) score protocol proposed by Armbruster and his colleagues (Avery, Richarrdson \& Jackson, 1979) and previously used by Hensley (1989). The placement (accuracy) score of serve was determined according to the target area within the court in which the ball landed (Armbruster, et al., 1979, see Figure 1). Serves landing in the designated half of the court were awarded 2 points; serves landing elsewhere in the service court were awarded 1 point, and those landing outside of the service court received a score of 0 . The accuracy of the each serve was checked and recorded by the tester.

The Heart Rate (HR) of the participant was also recorded by HR polar watch during the test (Kovacs, 2007). The equation of the estimated maximal heart rate (HRmax) was determined by subtracting subject's age from 220 (Estimated HRmax $=220-$ age) (Wilmore, \& Costill, 1994).

Figure 1. Experimental set-up showing position of subject (server), observers, radar gun, and target areas (serve from left-half court to right-half court, not drawn to scale).

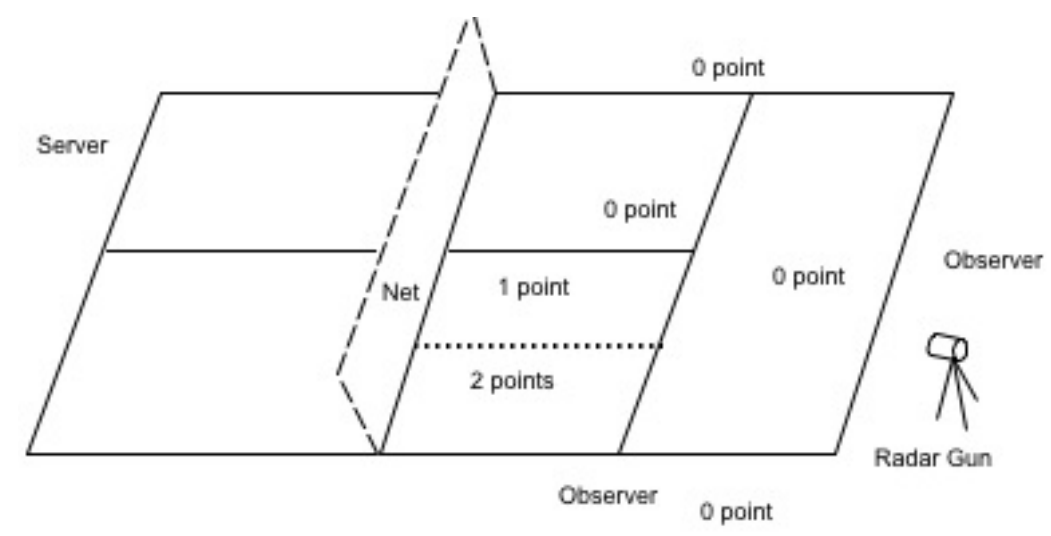




\section{Data Analysis}

SPSS 16.0 was applied to examine all statistical data. Descriptive statistics was used to examine respondent demographic characteristics (e.g., age, and height). Paired t test was conducted on the service performance (accuracy/ score and speed) before and after match-induced fatigue. The Kolmogorow Smirnow test was used for testing whether the variables were normally distributed. In all analyses, the significant was set at $\mathrm{p}=0.05$.

\section{Results}

An $18 \%$ deteriorate on first serve percentage was observed and the number of double faults increased from 17 to 26 after the protocol. Table 2 shows the descriptive results of our experiment. The mean HR and the maximal HR percentage during this study was 148.75 beats per minute and around $75 \%$, respectively. There was a decline in service score but an increase in RPE after match like protocol. In Table 3, there is a significant correlation between pre- and post- serve speed at .897 . However, no significant relationships are found between pre- and post-serve score, and between pre- and postRPE. In addition, no significant serve score and speed differences were found between pre- and post-test. There was a significant difference between pre- and post-RPE ( $\mathrm{p}=.006$, see Table 4).

Table 2. Descriptive Results of the Experiment.

\begin{tabular}{lcccccc}
\hline & N & Min & Max & Mean & SD & Sig. \\
\hline Sc_Pr & 8 & 9 & 16 & 12.00 & 2.26 & $.20^{*}$ \\
Sc_Po & 8 & 7 & 15 & 10.88 & .80 & $.20^{*}$ \\
Sp_Pr & 8 & 74.00 & 121.00 & 99.95 & 18.53 & $.20^{*}$ \\
Sp_Po & 8 & 86.125 & 115.250 & 101.53 & 12.49 & .18 \\
RPE_Pr & 8 & 6 & 12 & 9.62 & 2.13 & .19 \\
RPE_Po & 8 & 9 & 16 & 12.62 & 2.26 & $.20^{*}$ \\
M_HR & 8 & 126 & 170 & 148.75 & 12.99 & -- \\
Peak HR & 8 & 159 & 211 & 185.00 & 14.93 & -- \\
HRmax $\%$ & 8 & .63 & .85 & .74 & .065 & -- \\
\hline
\end{tabular}

Note. Sc_Pr= Pretest Score, Sc_Po= Posttest Score, Sp_Pr= Pretest Speed, Sp_Po=Posttest Speed, RPE_Pr=Pretest of RPE, RPE_Po=Posttest of RPE, M_HR=Mean Heart Rate,

Table 3. Paired Samples Correlations of Paired t test on Score, Speed, and RPE.

\begin{tabular}{lccc}
\hline & N & Correlation & Sig. \\
\hline Pair 1 Sc_Pr - Sc_Po & 8 & -.270 & .518 \\
Pair 2 Sp_Pr - Sp_Po & 8 & .897 & $.003^{*}$ \\
Pair 3 RPE_Pr- RPE_Po & 8 & .499 & .208 \\
\hline
\end{tabular}

*Correlation is significant at the 0.05 level 
Table 4. Paired Samples Test on Score, Speed, and RPE.

\begin{tabular}{|c|c|c|c|c|c|c|c|c|}
\hline & \multicolumn{8}{|c|}{ Paired Differences } \\
\hline & \multicolumn{8}{|c|}{$95 \% \mathrm{CI}$ of } \\
\hline & & & & Confiden & & & & Sig. \\
\hline & M & SD & SE & Lower & Upper & $\mathrm{t}$ & $\mathrm{df}$ & \\
\hline $\begin{array}{l}\text { Pair } 1 \text { Sc_Pr-Sc_Po } \\
\text { Pair } 2\end{array}$ & $\begin{array}{l}1.125 \\
-1.578\end{array}$ & $\begin{array}{l}4.051 \\
9.169\end{array}$ & $\begin{array}{l}1.432 \\
3.242\end{array}$ & $\begin{array}{l}-2.261 \\
-9.244\end{array}$ & $\begin{array}{l}4.512 \\
6.088\end{array}$ & $\begin{array}{l}.785 \\
-.487\end{array}$ & $\begin{array}{l}7 \\
7\end{array}$ & $\begin{array}{l}.458 \\
.641\end{array}$ \\
\hline $\begin{array}{l}\text { Sp_Pr-Sp_Po } \\
\text { Pair } 3\end{array}$ & -3.000 & 2.204 & .779 & -4.843 & -1.157 & -3.850 & 7 & $.006^{*}$ \\
\hline RPE_Pr-RPE_Po & & & & & & & & \\
\hline
\end{tabular}

${ }^{*}$ Correlation is significant at the 0.05 level

Note. $\mathrm{SE}=$ Standard Error, $\mathrm{CI}=$ Confidence Internal

\section{Discussion}

The purpose of this study was to explore whether fatigue following a match-like protocol would influence service performance (service accuracy and speed). The increasing RPE after the protocol suggests an increase in exercise intensity over the period of the match. The post mean RPE was 12.6 indicating participants felt slightly hard after the match-induced fatigue (Davey et al., 2002). The mean HR throughout the experiment was about $148.75 \pm 12.992$ beats per minute and this result was consistent with previous research findings (Bergeron, Maresh, Kraemer, et al., 1991; Docherty D., 1982). Furthermore, HRmax percentage was at around $75 \%$, which means our match-like protocol induced an intermittent exercise intensity or slight fatigue (Bergeron et al., 1991; Fernandez-Fernandez, Sanz-Rivas, FernandezGarcia \& Mendez-Villanueva, 2008). The collected data on HR and RPE consistently demonstrated that the protocol in our study induced a slight fatigue. It also showed that an RPE scale correlates strongly with the metabolic responses of HR which has been reported by Edwards, Melcher, Hesser, Wigertz, and Ekelund (1972).

The decline in first serve percentage and an increase in double faults after protocol implied some level of serve performance deterioration. The accuracy of serve though decreased after the 1.5 hours match-like protocol, no significant difference was found in both the preand post-test. There was also no significant difference between both the pre- and post- serve speed. These findings suggested that the match-like protocol though deteriorate the service performance (e.g., increase double faults, and decrease service score), it had no significant impact on tennis players' serve performance. Our result was consistent with the research findings conducted by Ferrauti et al. (2001). On the contrary, other previous studies showed fatigue would reduce service performance (Vergauwen, Spaepen, Lefevre \& Hespel, 1998; Davey, Thorpe \& Williams, 2002; Davey, Thorpe \& Williams, 2003). Thus, more empirical studies should be conducted in the future to explore the relationship between fatigue and tennis performance.

The participants can be considered to be fatigued when RPE of 15 is reached (Pandolf, Billings, Drolet, Pimental, \& Sawka, 1984; Tripp, Boswell, Gansneder, \& Shultz, 2004). No serve performance difference was found in our study may be due to the insufficient fatigue since the post mean RPE was 12.62 in our experiment. On the contrary, Ferrauti et al. (2001) demonstrated that fatigued tennis players can skillfully perform even with a volitional fatigue RPE of 20. However, the protocol for inducing fatigue in their study was not a match-like protocol, which might lead to different findings (Hornery et al., 2007) since the use of match-like fatigue protocols could have the advantage of mimicking the demands of sporting activity (Ribeiro, Santos, Gonc, Goncalves, \& Oliveira, 2008). In addition, the minimum tennis playing experience was around 0.30 year (see Table 1), thus, participants' tennis skills might be very unstable. The small sample and limited tennis experiences $(2.038+1.458$ years $)$ may also affected the finding of our study. 


\section{Conclusions}

This study explored the effects of fatigue on the tennis serve performance and the protocol for inducing fatigue was a simulated tennis match, which lasted 1.5 hours. Our finding demonstrated that even fatigue inducted some decrement in number of double faults; it had no impact on the service performance, at least on the male college team players. In the future, study should be conducted by including more participants with varying tennis playing levels or experiences in order to explore the relationship between fatigue (match-like fatigue protocol) and tennis skill performance. Furthermore, the female tennis players should be included in future study to explore if there was a gender effect.

\section{References}

Avery, C.A., Richarrdson, P.A., \& Jackson, A.W. (1979). A practicial tennis serve test: Measurement of skill under simulated game conditions. Research Quarterly, 50 (4), 554-564.

Bergeron, M. F., Maresh, C.M., Armstrong, L.E., Signorile, J.F., Castellani, J.W., Kenefick, R.W., LaGasse, K.E., \& Riebe, D.A. (1995). Fluid-electrolyte balance associated with tennis match play in a hot environment. International Journal of Sport Nutrition, 5, $5180-5193$.

Bergeron M.F., Maresh, C.M., Kraemer, W.J., Abraham. A., Conroy, B., \& Gabaree, C. (1991). Tennis: a physiological profile during match play. International Journal of Sport Medicine, 12 (5): 474-479.

Borg, G. (1998). Borg's perceived exertion and pain scales. Champaign, IL: Human Kinetics.

Chen,M. J., Fan, X., \& Moe, S. T. (2002). Criterionrelated validity of the Borg ratings of perceived exertion scale in healthy individuals: A meta-analysis. Journal of Sports Sciences, 20, 873 - 899.

Cohen, D.B., Mont, M.A., Campbell, K.R., Vogelstein, B.N. \& Loewy, J.W. (1994). Upper extremity physical factors affecting tennis serve velocity. American Journal of Sports Medicine, 22, 746-750.
Davey, P.R., Thorpe, R.D., \& Williams, C. (2003). Simulated tennis match-play in a controlled environment. Journal of Sports Science, 21, 459-467.

Davey, P.R., Thorpe, R.D., \& Williams, C. (2002). Fatigue decreases skilled tennis performance. Journal of Sports Science, 20, 311-318.

Docherty D. (1982). A comparison of heart rate responses in racquet games. British Journal of Sports Medicine, 16 (2), 96-100.

Edwards, R. H., Melcher, A., Hesser, C. M., Wigertz, O., \& Ekelund, L. G. (1972). Physiological correlates of perceived exertion in continuous and intermittent exercise with the same average power output. European Journal of Clinical Investigation, 2, 108114.

Fernandez-Fernandez, J., Sanz-Rivas, D., Fernandez-Garcia, B., \& Mendez-Villanueva, A. (2008). Match activity and physiological load during a clay-court tennis tournament in elite female players, Journal of Sports Sciences, 14, 1589 -1595.

Ferrauti, A., Pluim, B., \& Weber, K. (2001). The effect of recovery duration on running speed and stroke quality during intermittent training drills in elite tennis players. Journal of Sports Sciences, 19, 235242.

Gioftsidou, A., Malliou, P., Pafis, G., Beneka, A., Godolias, G. \& Maganaris, C.N.(2006). The effects of soccer training and timing of balance training on balance ability, European Journal of Applied Physiology, 96(6), 659-664.

Hensley, L. (1989). Tennis for Boys and Girls: Skills Test Manual. Reston, Virginia: American Alliance for Health, Physical Education, Recreation, and Dance.

Hornery,D.J., Farrow, D., Mujika, I., \& Young, W. (2007). Fatigue in tennis: Mechanisms of fatigue and effect on performance. Sports Medicine, 37(3), 199-212.

Knudson, D.V., Noffal, G.J., Bahamonde, R.E., Bauer, J.A., \& Blackwell, J.R. (2004). Stretching has no effect on tennis serve performance. Journal of Strength and Conditioning Research, 18(3), 654-656. 
Kovacs, M.K. (2006). Applied physiology of tennis performance. British Journal of Sports Medicine, 40(5), 381-386.

Kovacs, M.S. (2007). Tennis physiology: Training the competitive athlete. Sports Medicine, 37 (3), 189-198.

Murray, T.A., Cook, T.D., Werner, S.L., Schlegel, T. F. \& Hawkins, R.J. (2001). The effects of extended play on professional baseball pitchers. American Journal of Sports Medicine, 29, 137-142.

Russell, W. D., \& Weeks, D. L. (1994). Attentional style in ratings of perceived exertion during physical exercise. Perceptual and Motor Skills, 78, 779 783.

Pandolf, K. B., Billings, D. S., Drolet, L. L., Pimental, N. A., \& Sawka, M. N. (1984). Differential ratings of perceived exertion and various physiological responses during prolonged upper and lower body exercise. European Journal of Applied Physiology and Occupational Physiology, 53, 5-11.

Perry, A.C., Wang, X.W., Feldman, B.B., Ruth, T., \& Signorile, J. (2004). Can Laboratory-based tennis profiles predict field tests of tennis performance? Journal of Strength and Conditioning Research, 18(1), 136-143.

Ribeiro, F., Santos, F., Gonc, P., Goncalves, P., \& Oliveira, J. (2008). Effects of volleyball match-induced fatigue on knee joint position sense. European Journal of Sport Science, 8(6) 397-402.

Schomer, H. H. (1987). Mental strategy training programme for marathon runners. International Journal of Sport Psychology, 18, 133 - 151.

St Clair Gibson, A., Baden, D.A., \& Lambert, M.I. (2003). The conscious perception of the sensation of fatigue. Sports Medicine, 33(3), 167-176.
Teriber, F.A., Lott, J., Duncan, J., Slavens, G., \& Davis, H. (1998). Effects of theraband and lightweight dumbbell training on shoulder rotation torque and serve performance in college tennis players. American Journal of Sports Medicine, 26, 510-515.

Tripp, B. L., Boswell, L., Gansneder, B. M., \& Shultz, S. J. (2004). Functional fatigue decreases 3-dimensional multijoint position reproduction acuity in the overhead-throwing athlete. Journal of Athletic Training, 39, 316-320.

Vergauwen, L., Spaepen, A.J., Lefevre, J., \& Hespel, P. (1998). Evaluation of stroke performance in tennis. Medicine and Science in Sports and Exercise, 30(8), 12811288.

Wilmore, J.H., \& Costill, D.L. (1994). Physiology of sport and exercise. Human Kinetics, Champaign.

Footnotes:

1. Note. Sc_Pre= Pretest Score, Sc_Pos= Posttest Score, Sp_Pre $=$ Pretest Speed, Sp_Pos=Posttest Speed, RPE_ Pre=Pretest of RPE, RPE_Pos=Posttest of RPE, M HR=Mean Heart Rate

2. Note. $\mathrm{SE}=$ Standard Error, $\mathrm{Cl}=$ Confidence Internal

\section{Correspondence}

\section{Chunxiao}

Graduate School, HKIEd,

10 Tai Po Lo Pin Road,

Tai Po, N.T., Hong Kong

Email: cxli@ied.edu.hk

\section{通訊位址}

\section{李春曉}

香港, 新界, 大埔,

大埔露屏路 10 號,

香港教育學院, 研究生院

電子郵箱：cxli@ied.edu.hk 